Vol. 1 | No. 2 | April 2020 | Hal. 92 - 97

\title{
PENGEMBANGAN OBJEK DAN DAYA TARIK WISATA ALAM COBAN SRENGENGE SEBAGAI DAERAH TUJUAN WISATA
}

\author{
Artono Raharjo ${ }^{1}$, Ainun Feroza Hadi ${ }^{2}$, Dinda Aulia Fitri ${ }^{3}$, Khullatus Sofiyah ${ }^{3}$, Tutik \\ Marzukoh $^{3}$, Ajis Santoso', Lalu Ahmad Zainuddin Alfani' ${ }^{2}$, Zamroni ${ }^{4}$, Anhar ${ }^{4}$, Suryo \\ Wisnu Murti' ${ }^{1}$ Dicky Firmansyah ${ }^{5}$ \\ ${ }^{1}$ Fakultas Teknik, Universitas Islam Malang \\ ${ }^{2}$ Fakultas Keguruan dan Ilmu Pendidikan, Universitas Islam Malang \\ ${ }^{3}$ Fakultas Agama Islam, Universitas Islam Malang \\ ${ }^{4}$ Fakultas Ekonomi dan Bisnis, Universitas Islam Malang \\ ${ }^{5}$ Fakultas Kedokteran, Universitas Islam Malang \\ Korespondensi email: artonor@unisma.ac.id
}

\begin{abstract}
ABSTRAK
Tujuan dari program ini adalah untuk mengembangkan wisata lokal di Desa Tirtomarto Kecamatan Ampelgading Kabupaten Malang. Di daerah ini terdapat wisata alam yaitu Coban Srengenge. Lokasi coban srengenge ini tidak jauh dari pemukiman warga. Coban srengenge ini terdapat 3 lokasi coban. Melihat potensi yang ada dari coban tersebut, kita sebagai mahasiswa KKN PPM TEMATIK yang mengabdi di Desa Tirtomarto Kecamatan Ampelgading Kabupaten Malang turut serta membantu dalam proses pengembangan coban srengenge tersebut bekerja sama dengan pemerintah sekitar. Pengembangan coban srengenge yang dilakukan yaitu berupa pembangunan gapura dan pembersihan coban srengenge sekaligus penanaman tanaman di area spot foto dan bibit bibit pohon di area coban srengenge.
\end{abstract}

Kata Kunci: coban srengenge; pengembangan; wisata.

\section{PENDAHULUAN}

Pariwisata menjadi salah satu primadona bagi negara-negara dalam meningkatkan sumber pendapatannya diluar dari migas dan pajak. Saat ini Indonesia sebagai salah satu negara berkembang mulai mempromosikan negaranya guna menarik pandangan mata dunia lain, hal ini dimaksudkan agar Indonesia semakin terkenal bagi warga/penduduk negara lain untuk berkunjung ke Indonesia. Promosi-promosi yang dilakukan adalah menjual keragaman wisata dan budaya Indonesia, hal inilah ditanggapi positif dengan banyaknya wisatawan dari mancanegara yang berkunjung ke Indonesia (Natan, 2016) (Fitriani, 2018).

Indonesia yang memiliki keragaman budaya dan wisata melimpah itu mampu mengatasi masalah-masalah mendasar dengan penguatan ekonomi dari penerimaan devisa/pendapatan daerahnya dengan itulah sebagai negara yang memiliki keragaman melimpah Indonesia dapat mengembangkan potensinya, misalnya dari segi pariwisata sebab wisatawan yang berkunjung ke Indonesia mencari atau menikmati keindahan pariwisata Indonesia sehingga memberikan efek domino bagi dalam maupun luar negeri, bila dari luar negeri negara kita semakin terkenal maka bagi dalam negeri negara kita 
dapat menambah devisa guna mengangkat kesejahteraan masyarakat yang ada saat ini (Hawing et al., 2019).

Pariwisata memiliki peran yang besar dalam pembangunan nasional. Karena selain menghasilkan pendapatan dan sekaligus sebagai penghasil devisa, sektor pariwisata berkaitan erat dengan penanaman modal asing. Turis-turis yang datang ke Indonesia adalah termasuk mereka yang berhubungan bisnis dengan Indonesia (Risman et al., 2016) (Hakim, 2010).

Usaha pariwisata adalah kegiatan yang bertujuan menyelenggarakan jasa pariwisata atau menyediakan atau mengusahakan objek dan daya tarik wisata, usaha barang pariwisata dan usaha lain yang terkait dengan bidang tersebut. Industri pariwisata adalah suatu susunan organisasi, baik pemerintah maupun swasta, yang terkait dalam pengembangan, produksi dan pemasaran produk suatu layanan untuk memenuhi kebutuhan dari orang yang sedang berpergian (Wolah, 2016).

Pariwisata di daerah-daerah sangatlah banyak bila mampu memanfaatkan potensipotensi yang ada, pemerintah dan masyarakat daerah saling membantu dalam pengembangannya tersebut sehingga akan mengangkat segi ekonomi, budaya dan pendidikan daerah itu (Setiawan, 2015). Pariwisata sangatlah mampu dalam mengatasi masalah kesejahteraan bila dikembangkan secara professional (Primadany et al., 2013).

Kabupaten Malang merupakan merupakan salah satu wilayah di Provinsi jawa Timur yang didalamnya terdapat berbagai potensi daerah serta kekayaan alam yang sangat potensial untuk dikembangkan (Sugianto \& Sholihah, 2018). didalam kabupaten malang terdapat banyak sekali daerah-daerah yang dinaungi oleh Pemerintah Kabupaten Malang. Salah satu daerah yakni Desa Tirtomarto yanng terletak di Kec. Ampelgading, Kab. Malang. Desa Tirtomarto memiliki luas tanah 697,70 hektar, luas tanah pemukiman 61,3730 Ha, dengan ketinggian tanah di atas permukaan laut 650 meter, dengan laus tanah sawah 105,6710 Ha. Dengan batas utara Tawang Agung, sebelah selatan Purwoharjo, sebelah timur Tirtomoyo serta sebelah barat yakni Tamanasri.

Desa Tirtomarto terletak dititik koordinat 112.780834 BT / -7.96134 LS. Dengan iklim tropis serta struktur tanah lempungan dan deburan sehingga di desa ini sangat cocok sekali digunakan untuk bercocok tanam kopi, salak, durian, singkong serta talas. Selain bercocok tanam juga hasil dari kebun tersebut diolah lagi seperti salak menjadi usaha rumahan kripik salak yang didistribusikan antar daerah lokal.

Selain hasil kebun, di desa Tirtomarto juga terdapat banyak wisata. Salah satu kekayaan alam yang sangat dapat dikembangkan adalah berwujud wisata. Wisata yang dimaksud adalah wisata coban srengenge yang terletak di desa Tirtomarto Kecamatan Ampelgading Kabupaten Malang yang merupakan wisata unggulan di desa ini. Keindahan coban serta kejernihan air terjun yang dimiliki coban ini menjadikan objek wisata ini sangat diperlukan pengembangannya (Fathani, 2019).

Pengembangan wisata coban srengenge ditandai juga dengan semakin meningkatnya wisatawan yang berkunjung serta adanya pembangunan fasilitas di sekitar coban srengenge. Selain itu juga adanya renovasi, dan pengelolaan fasilitas sarana prasaranauntuk menunjang perbaikan fasilitas di coban srengenge.

KKN-PPM Unisma ditempatkan diberbagai daerah di Kabupaten Malang salah satunya di Desa Tirtomarto Ampelgading. Setelah melakukan survey lokasi coban srengenge kelompok 16 menemukan bahwa arah ke lokasi coban srengenge tidak ditemukan gapura yang menjadi ikon coban srengenge. Ikon gapura dapat menjadikan simbol suatu tempat wisata agar wisatawan dapat dengan mudah menemukan tempat wisata tersebut serta tidak ditemukannya denah lokasi coban srengenge. Coban srengenge 
terdiri dari 3 coban yang berada di satu daerah akan tetapi lokasi letaknya berbeda. Perlu adanya denah jalan agar pengunjung ke coban yang akan di tuju.

Tujuan dari pengembangan objek dan daya tarik wisata alam melalui pembuatan gapura di Coban Srengenge adalah untuk membangun gapura di pintu masuk coban srengenge, pembuatan denah, serta penanaman tanaman untuk mengembangkan pariwisata coban srengenge, menaikkan minat wisatawan untuk berkunjung ke coban srengene, serta meningkatkan kesadaran masyarakat dalam pengelolaan dan pembangunan kepariwisataan kecamatan Ampelgading.

\section{METODE}

Program pengembangan objek dan daya tarik wisata alam Coban Srengenge ini dilaksanakan di Desa Tirtomarto, Kecamatan Ampelgading Kabupaten Malang di mulai pada tanggal 14 Februari 2020 sampai dengan tanggal 29 Februari 2020. Kegiatan ini dilakukan bersama antara Dosen Pendamping Lapangan dan Mahasiswa kelompok 16 yang dimulai dengan melakukan kegiatan observasi lapangan dan diskusi bersama Pokdarwis desa terkait rencana pembangunan, pengelolaan dan pengembangan objek dan daya tarik wisata alam di Desa Tirtomarto.

Adapun metode yang digunakan adalah berbasis kelompok artinya kelompok akan digunakan sebagai media belajar dan pendampingan bersama pokdarwis Desa Tirtomarto, perencanaan kegiatan, pelaksanaan kegiatan serta monitoring kegiatan.

Kegiatan KKN-PPM Tematik ini dikhususkan dalam pengembangan objek dan daya tarik wisata alam yaitu tepatnya di Coban Srengenge yang terdapat di Desa Tirtomarto, Kecamatan Ampelgading yang dilakukan secara bersama-sama antara pihak Mahasiswa dengan perwakilan pokdarwis Desa Tirtomarto. Kegiatan pengembangan objek ini meliputi kegiatan pembersihan area lokasi coban dan pembangunan gapura. berikut:

Adapun tahapan yang dilakukan dalam pelaksanaan kegiatan ini yaitu sebagai

\section{Survei Lokasi}

Survei lokasi ini dilakukan bertujuan untuk menyesuaikan antara kegiatan dengan tema tematik yang telah dipilih serta dapat dijadikan objek gambaran apakah ada potensi lainnya yang terdapat di lokasi Coban Srengenge yang dapat dikembangkan atau ditambahkan dalam pelaksanaan kegiatan yang telah direncakan.

\section{Diskusi Bersama Pokdarwis Desa Tirtomarto}

Kegiatan Diskusi ini dilakukan oleh perwakilan dari Mahasiswa KKN yang bertemakan "MAS DARWIS" dan perwakilan Pokdarwis Desa Tirtomarto. Kegiatan diskusi ini dilakukan guna dapat menyatukan antara pemikiran ide rancangan yang dipaparkan oleh Mahasiswa yang diskusikan bersama pokdarwis Desa Tirtomarto agar rencana yang ingin dikerjakan sesuai dengan harapan kedua belah pihak dan dapat diselesaikan sesuai dengan apa yang telah ditargetkan sebelumnya.

\section{HASIL DAN PEMBAHASAN}

Kegiatan yang dilakukan dalam pengembangan wisata coban srengenge di desa tirtomarto kecamatan ampelgading kabupaten malang diantaranya:

\section{Pembuatan Gapura Coban Srengenge}

Pembuatan gapura di coban srengenge dilakukan agar para pengunjung dapat tertib memasuki area pantai melalui gapura tersebut. selain itu juga untuk menambah daya tarik bagi wisatawan dan menjadi nilai lebih bagi wisata coban srengenge. Gapura dibuat dengan proses pengecoran, pengecatan hingga pemasangan tulisan coban srengenge yang pada gapura. 
Dalam pengkerjaan gapura dibantu oleh bapak bapak pokdarwis coban srengenge desa tirtomarto. Realisasi program kerja pembangunan gapura di coban srengenge mulai dikerjakan pada tanggal 14 Februari 2020. Kami menjadwalkan pengkerjaan gapura coban srengenge dari jam 08.00 - 11.00 kemudian jam 13.00 16.00. Dalam pengerjaannya dibantu oleh kelompok KKN lain yang juga ber KKN di desa Tirtomarto. Dan juga dibantu oleh bapak bapak pokdarwis coban srengenge Desa Tirtomarto. Pembangunan gapura coban srengenge ini selesai pada tanggal 29 februari 2020.

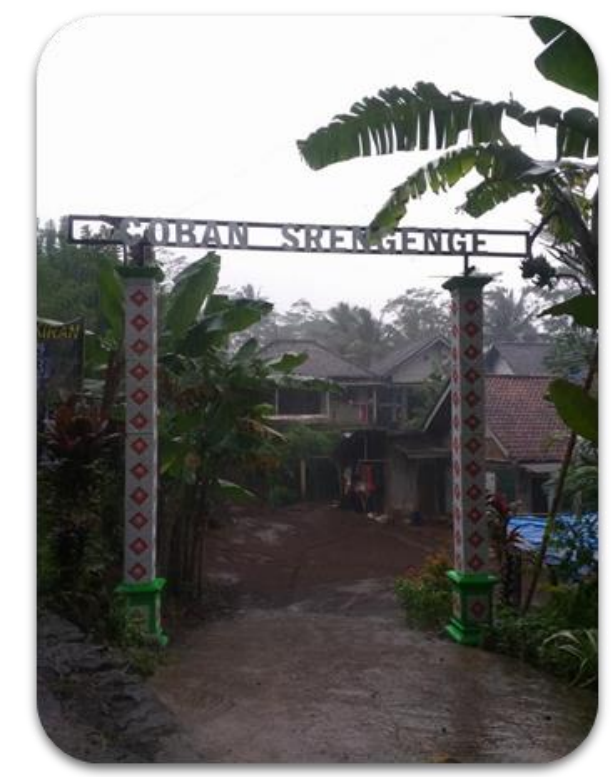

Gambar 1. Pembenahan gapura coban srengenge (dok. KKN-PPM Kel. 16)

\section{Pembersihan Coban Srengenge Sekaligus Penanaman Tanaman di Area Spot Foto dan Bibit Bibit Pohon}

Pembersihan coban srengenge dilakukan agar coban srengenge tetap terjaga kebesihannya, sehingga pengunjung merasa aman, nyaman dan tidak merasa risih dengan lingkungan coban srengenge. Tanaman yang ada di area spot foto yang kurang terawat, maka dari itu kita berinisiatif untuk memperbaharui tanaman tanaman yang ada di spot foto. Penanaman bibit bibit pohon di area coban srengenge dilakukan agar coban srengenge semakin rindang, sejuk dan terjaga kehijauannya.

Program pembersihan coban srengenge sekaligus penanaman tanaman di area spot foto dan bibit pohon di area lingkungan coban srengenge berjalan sesuai dengan rencana. Pelaksanaan proker ini juga dibantu oleh kelompok lain yang juga ber - KKN di Desa Tirtomarto. Tanaman untuk spot foto dan bibit bibit pohon yang kita tanam di coban srengenge tersebut disediakan oleh pokdarwis coban srengenge. 


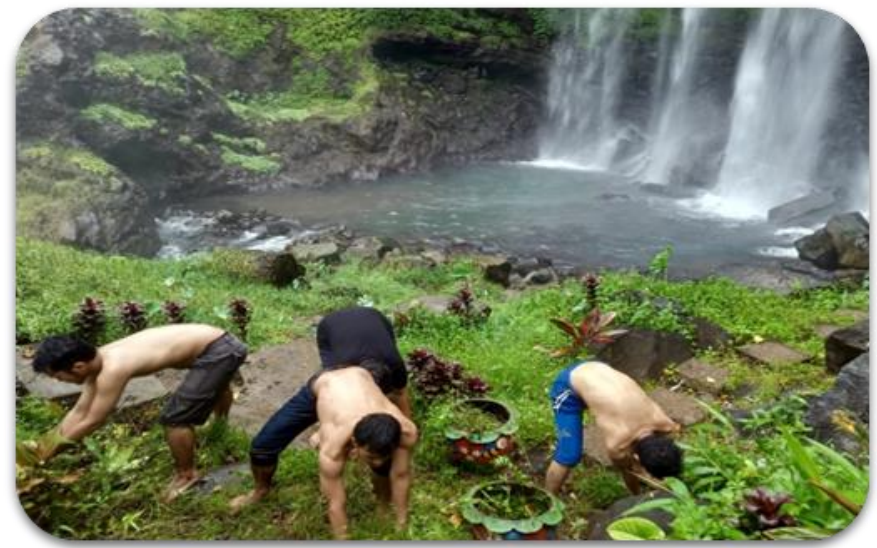

Gambar 2. pembersihan area coban srengenge (dok. KKN-PPM Kel. 16)

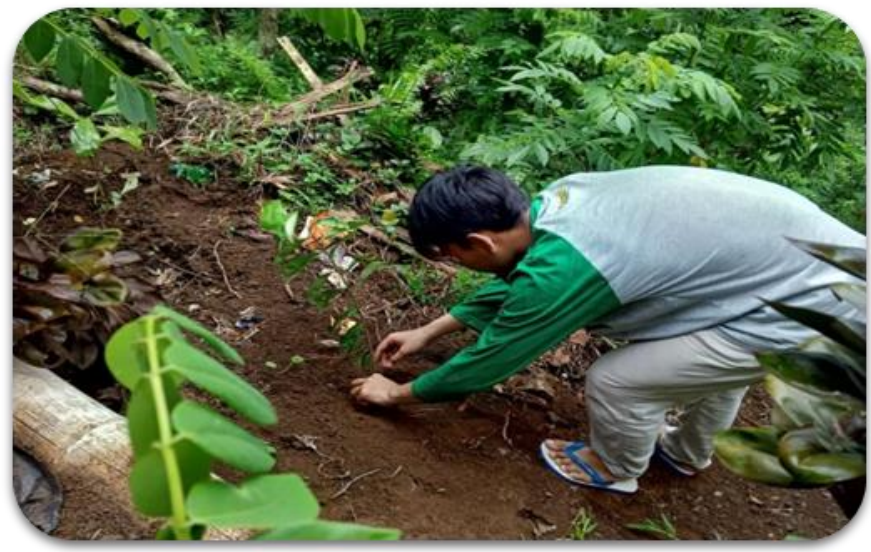

Gambar 3. Penanaman bibit pohoh di coban srengenge (dok. KKN-PPM Kel. 16)

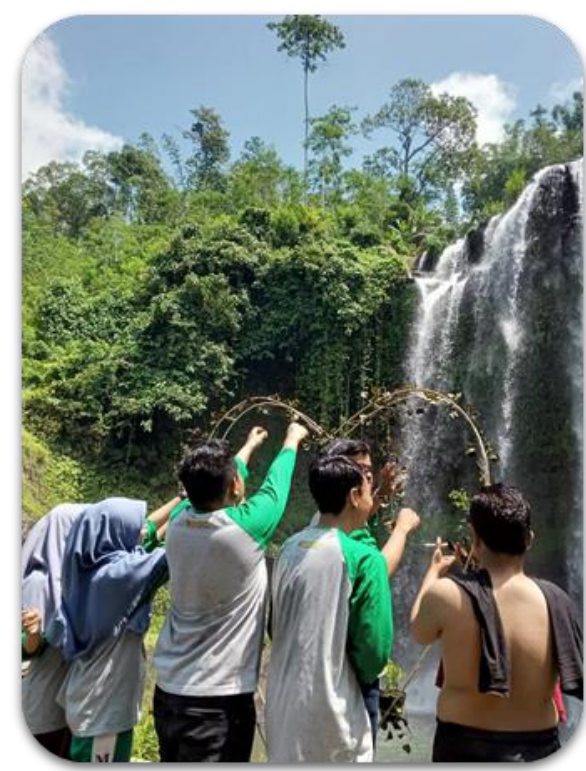

Gambar 4. Penanaman tanaman di spot foto coban srengenge (dok. KKN-PPM Kel. 16)

\section{KESIMPULAN}

Berdasarkan hasil kegiatan pengembangan objek wisata di desa tirtomarto kecamatan Ampelgading oleh Mahasiswa KKN PPM Tematik, diperoleh kesimpulan sebagai berikut: 
1. Desa Tirtomarto Kecamatan Ampelgading memiliki aset wisata coban yang dapat dikembangkan.

2. Fasilitas yang dibangun di coban srengenge memberikan dampak positif yaitu menarik perhatian para wisatawan agar dapat berkunjung ke coban srengenge.

3. Pemerintah daerah dan warga setempat mendukung keberlanjutan dari kegiatan pengembangan wisata coban srengenge. Hal ini ditandai dengan adanya antusias dari warga maupun aparatur desa dalam kegiatan pengembangan tersebut

Semoga dengan adanya kerjasama antara Mahasiswa KKN PPM Tematik Unisma kelompok 16 dengan Desa Tirtomarto di Kecamatan Ampelgading, diharapkan dapat dijadikan sebagai salah satu desa yang dapat dikembangkan dengan potensi yang ada di Desa tersebut.

\section{DAFTAR RUJUKAN}

Fathani, A. H. (2019). Pemberdayaan Masyarakat Untuk Mewujudkan Desa Mandiri Dan Sejahtera Berbasis Entrepreneur Melalui Pemanfaatan Buah Salak. Jurnal Pembelajaran Pemberdayaan Masyarakat (JP2M), 1(1), 55-58. https://doi.org/10.33474/jp2m.v1i1.5008

Fitriani, P. (2018). Persepsi Masyarakat Terhadap Potensi Obyek Wisata Puncak Ahuawali di Desa Ahuawali Kecamatan Puriala Kabupaten Konawe. Jurnal Penelitian $\begin{array}{lll}\text { Pendidikan } \quad \text { Geografi, } & \text { 84), }\end{array}$ https://doi.org/10.1017/CB09781107415324.004

Hakim, L. (2010). Industri Pariwisata dan Pembangunan Nasional. Among Makarti, 3(5), 70-78. https://jurnal.stieama.ac.id/index.php/ama/article/view/18

Hawing, H., Mutmainnah, \& Nengsi R, R. (2019). Kemitraan Pemerintah Daerah Dengan Badan Promosi Pariwisata Daerah Dalam Pemasaran Objek Wisata Permandian Alam Ompo Kabupaten Soppeng. Jurnal Komunikasi Dan Organisasi (J-KO), 1(1), 1824. https://journal.unismuh.ac.id/index.php/jko/article/view/1771

Natan, N. (2016). Prospek Pariwisata Morotai. Media Wisata, 14(1), 305-316. https://doi.org/10.36276/mws.v14i1.150

Primadany, S. R., Mardiyono, \& Riyanto. (2013). Analisis Strategi Pengembangan Pariwisata Daerah (Studi Pada Dinas Kebudayaan Dan Pariwisata Daerah Kabupaten Nganjuk). Jurnal Administrasi Publik Mahasiswa Universitas Brawijaya, 1(4), 135-143.

Risman, A., Wibhawa, B., \& Fedryasyah, M. (2016). Kontribusi Pariwisata Dalam Peningkatan Kesejahteraan Masyarakat Indonesia. Prosiding Penelitian Dan Pengabdian Kepada Masyarakat, 3(1), 1-154. https://doi.org/10.24198/jppm.v3i1.13622

Setiawan, I. (2015). Potensi Destinasi Wisata Di Indonesia Menuju Kemandirian Ekonomi. Prosiding Seminar Nasional Multi Disiplin Ilmu \& Call For Papers UNISBANK (SENDI_U), 978-979. https://www.unisbank.ac.id/ojs/index.php/sendi_u/article/view/3321

Sugianto, A., \& Sholihah, A. (2018). Kelompok Petani Jamur Tiram Putih Di Desa Blayu, Kecamatan Wajak, Kabupaten Malang. Jurnal Inovasi Hasil Pengabdian Masyarakat (JIPEMAS), 1(2), 129-136. https://doi.org/10.33474/jipemas.v1i2.1517

Wolah, F. F. C. (2016). Peranan Promosi Dalam Meningkatkan Kunjungan Wisatawan Di Kabupaten Poso. Jurnal Acta Diurna, 5(2), 1-11. https://ejournal.unsrat.ac.id/index.php/actadiurnakomunikasi/article/view/11722 